\title{
Optimization of Plaque Forming Conditions for an Aeromonas hydrophila Lytic Bacteriophage
}

\author{
Sumeet Rai, Anuj Tyagi ${ }^{1}$, B. T. Naveen Kumar ${ }^{1}$ and Niraj Kumar Singh ${ }^{2}$ \\ ${ }^{1}$ Department of Aquatic Environment, College of Fisheries, \\ ${ }^{2}$ College of Animal Biotechnology, Guru Angad Dev Veterinary and \\ Animal Sciences University, Ludhiana 141004, Punjab, India \\ *Corresponding author
}

\begin{abstract}
A B S T R A C T
Recent emergence of antibiotic resistant bacteria has led to renewed interest in the phage

\section{Keywords}

Aeromonas hydrophila, Phage,

Plaque assay, Soft agar, Ionic concentration

\section{Article Info}

Accepted:

26 May 2020

Available Online:

10 June 2020 research for control of aquatic bacterial pathogens. Plaque assay is an important part of phage research. For some phages, the plaques could be very much turbid and small in size resulting in difficulties during phage isolation and enumeration. Present study investigated the effect of soft agar as well as $\mathrm{Ca}^{++}$and $\mathrm{Mg}^{++}$ion concentrations on plaque forming ability of a Aeromonas hydrophila lytic phage. At $0.2 \%$ soft agar, with $10 \mathrm{mM}$ of $\mathrm{CaCl}_{2}$ and $\mathrm{MgSO}_{4}$, mean $\pm \mathrm{SD}$ plaque size of $5.55 \pm 0.52 \mathrm{~mm}$ and counts of $(58 \pm 4)$ were significantly higher the other concentrations. However, increase of agar concentration by value of just $0.1 \%$ reduced the plaque diameters to less than one millimeter. No plaques could be observed at soft agar concentration of $\geq 4 \%$. High $\mathrm{CaCl}_{2}$ and $\mathrm{MgSO}_{4}$ concentrations also affected plaque morphology, as plaques were found to be very much uniform and clear up to $25 \mathrm{mM}$, but turned to turbid and irregular size at $100 \mathrm{mM}$ of $\mathrm{CaCl}_{2}$ and $\mathrm{MgSO}_{4}$. This study provides important insights to optimize plaque assay for phages forming turbid and micro sizes plaques leading to their efficient utilization in phage therapy in aquaculture.
\end{abstract}

\section{Introduction}

Propagation of lytic bacteriophage in a confluent bacterial lawn results in the formation of a circular zone of clearing (plaque) due to multiple rounds of phage infection, multiplication and release events in its close vicinity. Plaque formation is important for initial confirmation of lytic activity of phage, phage purification, quantification, and mutant detection. Classical double agar overlay plaque assay (also known as double layer assay) involves mixing of appropriate phage dilutions, host bacterium and molten soft agar ("top agar") followed by pouring on a standard agar ("bottom agar") plate.

After solidification and incubation, plaques in the confluent bacterial lawn in top agar can be visualized by the naked eye (Kropinski et al., 2009). 
However, some phages may produce very much turbid and difficult to detect micro plaques during double layer assay (Mullan, 2002). Lack of visible plaque formation by phages can make their purification and quantification a very challenging task (Santos et al., 2009). The present study was carried out to standardize the plaque forming conditions for a Aeromonas hydrophila lytic phage.

\section{Materials and Methods}

\section{Initial phage enrichment and isolation}

Initial enrichment of $A$. hydrophila specific phage from water samples was performed as per previously described protocols(Vinod et al., 2006). After confirmation of phage lytic activity by spotting a $10 \mu \mathrm{l}$ aliquot on $A$. hydrophila lawn, $100 \mu \mathrm{l}$ of filtered phage lysate was serially diluted in phage buffer (10

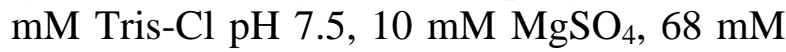
$\mathrm{NaCl}, 1 \mathrm{mM} \mathrm{CaCl}_{2}$ ), and mixed with $900 \mu \mathrm{l}$ of young $A$. hydrophila culture $\left(\mathrm{OD}_{600} 0.5\right.$ $0.6)$ for double layer assay.

The phage-bacterial mixture was incubated at room temperature for $10 \mathrm{~min}$, and further mixed with $4 \mathrm{ml}$ of molten top soft agar (LB with $0.4 \%$ agar). The entire mixture was overlaid on the bottom agar plate (LB with $1.5 \%$ agar). After overnight incubation at 30 ${ }^{\circ} \mathrm{C}$, a single plaque (representing a single type of phage) was picked up, further enriched in A. hydrophila host culture and designated as D9 phage.

\section{Optimization of plaque forming conditions}

Though D9 phage isolated by above protocol was able to show lytic activity against $A$. hydrophila in broth cultures as well as during lawn assay, post isolation it stopped forming visible plaques during subsequent rounds of double layer assay.
Thus, we tried to optimize the plaque forming conditions for D9 phage by experimenting with different agar and ionic concentrations in top soft agar. For this purpose, LB broth was supplemented with $0.2 \%, 0.3 \%, 0.4 \%$ and $0.5 \%$ agar concentrations for preparation of top soft agars.

At each concentration of top soft agar, $\mathrm{CaCl}_{2}$ and $\mathrm{MgSO}_{4}$ at $0 \mathrm{mM}, 10 \mathrm{mM}, 25 \mathrm{mM}, 50$ $\mathrm{mM}, 75 \mathrm{mM}$ and $100 \mathrm{mM}$ were also used. LB broth supplemented with $1.5 \%$ agar and 10 $\mathrm{mM}$ each of $\mathrm{CaCl}_{2}$ and $\mathrm{MgSO}_{4}$ was used as bottom agar for all the assays. Basic steps of double layer assay were carried out as described by Kropinski and colleagues (Kropinski et al., 2009).

Briefly,200 $\mu \mathrm{l}$ of young bacterial cultures $\left(\mathrm{OD}_{600} 0.5\right.$ - 0.6)were mixed with $100 \mu \mathrm{l}$ diluted phage suspensions followed by incubation for $10 \mathrm{~min}$ to facilitate the attachment of phage particles to bacterial cells. The bacteria-phage suspension was further mixed with $3 \mathrm{ml}$ of top soft agar and poured on the bottom agar plate.

After overnight incubation at $30^{\circ} \mathrm{C}$, Plaque counts from 10 plates at each soft agar and ionic concentration were determined. Moreover, diameters of 10 numbers of the largest plaques from each plate were also measured. One-way ANOVA and t-test $(p<0.05)$ were used to determine the statistical significance of the difference in plaque sizes and counts under various experimental conditions.

\section{Results and Discussion}

The concentration of soft top agar had considerable effects on plaque forming capabilities of D9 phage. At $0.2 \%$ agar concentration, D9 formed largest plaques with overall mean \pm SD value of $4.01 \pm 1.13 \mathrm{~mm}$ just after $10 \mathrm{~h}$ of incubation (Fig. 1, Table 1). 
However, increase of agar concentration by value of just $0.1 \%$ had a drastic effect as plaque diameters reduced to less than one $\mathrm{mm}$ at soft agar concentration of $0.3 \%$, and no increase in plaque size was detected even after $24 \mathrm{~h}$ of incubation.

At soft agar concentrations of $0.4 \%$ and $0.5 \%$, no visible plaques were observed even after $24 \mathrm{~h}$ of incubation. The concentration of soft agar also had a considerable effect on plaque forming unit (PFU) counts, as overall PFUs of $45 \pm 11($ mean $\pm \mathrm{SD})$ at $0.2 \%$ agar concentration were the significantly higher than the corresponding value of $19 \pm 11$ at $0.3 \%$ agar concentration (t-test, $p<0.05$ ).

In addition to inherent characteristics of phages such as latent period and burst size etc., physiological factors such as phage diffusivity and adsorption of phage on the bacterial host may also affect plaque formation (Abedon and Yin, 2009).

It has also been proposed that at lower agar concentrations, high diffusivity enables the phage to infect and lyse more numbers of host cells in the surrounding area resulting in larger size plaques (Mullan, 2002).

Serwer and colleagues reported that after initial isolation, a Bacillus thuringiensis phage 0305 48 -36was able to form visible plaques only at agarose concentration of $0.25 \%$ or less in the top layer(Serwer et al., 2007).

In our study, the largest plaques were observed at agar concentration of $0.2 \%$, and plaque size reduced drastically (to $<1 \mathrm{~mm}$ ) at agar concentration of $0.3 \%$.

We also investigated the effect of these $\mathrm{Ca}^{++}$ and $\mathrm{Mg}^{++}$ions on plaque formation by supplementing each level of soft agar with 0mM, $10 \mathrm{mM}, 25 \mathrm{mM}, 50 \mathrm{mM}, 75 \mathrm{mM}$ and
$100 \mathrm{mM}$ each of $\mathrm{CaCl}_{2}$ and $\mathrm{MgSO}_{4}$. In case of $0.2 \%$ soft agar, average plaque size of 5.55 $\pm 0.52 \mathrm{~mm}($ mean $\pm \mathrm{SD})$ at $10 \mathrm{mM} \mathrm{CaCl}_{2}$ and $\mathrm{MgSO}_{4}$ concentrations was significantly higher than corresponding values at $0 \mathrm{mM}$, $25 \mathrm{mM}, 50 \mathrm{mM}, 75 \mathrm{mM}$ and $100 \mathrm{mM}$ of $\mathrm{CaCl}_{2}$ and $\mathrm{MgSO}_{4}$ (ANOVA and Duncan`s multiple range test, $p<0.05$ ) (Table 1).

Moreover, the addition of $\mathrm{CaCl}_{2}$ and $\mathrm{MgSO}_{4}$ also affected plaque morphology, as plaques were found to be very much uniform and clear up to $25 \mathrm{mM}$, but turned to turbid and irregular size at higher concentrations (Fig. $1)$.

No statistical test to understand the effect of $\mathrm{Ca}^{++}$and $\mathrm{Mg}^{++}$concentrations at $0.3 \%$ soft agar level could be performed, all the plaques were $<1.0 \mathrm{~mm}$ in size and could not be measured accurately. In addition to effect on plaque sizes, $\mathrm{Ca}^{++}$and $\mathrm{Mg}^{++}$ions also had significant effect on plaque counts, as $\mathrm{PFU}$ counts at $10 \mathrm{mM} \quad \mathrm{CaCl}_{2}$ and $\mathrm{MgSO}_{4}$ concentration were significantly (ANOVA and Duncan`s multiple range test, $p<0.05)$ higher than the others at both $0.2 \%$ and $0.3 \%$ agar levels.

Moreover, a declining trend in PFU counts was observed with an increase of ionic concentrations at both $0.2 \%$ and $0.3 \%$ agar levels (Table 1). Studies have reported that the presence of metal ions enhance the efficiency of phage to kill its bacterial host(Ma et al., 2018), and it supports our observation of large plaque formation in presence of $\mathrm{Ca}^{++}$and $\mathrm{Mg}^{++}$ions. Similar to our findings, Foddai and colleagues reported that phage counts increased up to $2 \mathrm{mM} \mathrm{CaCl}_{2}$, and showed declining trends at higher concentrations(Foddai et al., 2009). These results indicated that though the addition of divalent metal ions may improve plaque formation, higher concentrations may be detrimental to plaque formation. 
Table.1 Effect of soft agar and $\mathrm{Ca}^{++}, \mathrm{Mg}^{++}$ions concentrations on plaque sizes and counts of Aeromonas hydrophila lytic D9 phage

\begin{tabular}{|c|c|c|}
\hline \multirow{2}{*}{$\begin{array}{c}\mathrm{CaCl}_{2} \text { and } \mathrm{MgSO}_{4} \\
\text { concentrations }\end{array}$} & \multicolumn{2}{|c|}{ Plaque sizes $(\mathrm{mm})$ and counts $(\mathrm{PFU})$} \\
\hline & $0.2 \%$ soft agar & $0.3 \%$ soft agar \\
\hline $0 \mathbf{m M}$ & $3.50^{\mathrm{cd}} \pm 0.52,48^{\mathrm{b}} \pm 5$ & $<1.0,21^{\mathrm{bc}} \pm 4$ \\
\hline $10 \mathrm{mM}$ & $5.55^{\mathrm{a}} \pm 0.52,58^{\mathrm{a}} \pm 4$ & $<1.0,33^{\mathrm{a}} \pm 3$ \\
\hline $25 \mathrm{mM}$ & $3.46^{\mathrm{cd}} \pm 0.78,49^{\mathrm{b}} \pm 3$ & $<1.0,17 b^{c d} \pm 3$ \\
\hline $50 \mathrm{mM}$ & $4.38^{\mathrm{b}} \pm 0.87,45^{\mathrm{b}} \pm 4$ & $<1.0,23^{b} \pm 9$ \\
\hline $75 \mathrm{mM}$ & $4.14^{\mathrm{bc}} \pm 1.17,46^{\mathrm{b}} \pm 3$ & $<1.0,13^{\mathrm{cd}} \pm 5$ \\
\hline $100 \mathrm{mM}$ & $3.23^{\mathrm{d}} \pm 1.01,24^{\mathrm{c}} \pm 4$ & $<1.0,7^{\mathrm{d}} \pm 5$ \\
\hline Overall & $4.01 \pm 1.13,45^{1} \pm 11$ & $<1.0,19^{2} \pm 10$ \\
\hline
\end{tabular}

Superscripts $\mathrm{a}, \mathrm{b}, \mathrm{c} . \ldots .$. show a significant difference in plaque sizes and counts at different $\mathrm{CaCl}_{2}$ and $\mathrm{MgSO}_{4}$ concentrations (ANOVA and Duncan`s multiple range test, $p<0.05$ ).

Superscripts 1 and 2 show a significant difference in overall plaque counts at $0.2 \%$ and $0.3 \%$ soft agar levels (ttest, $p<0.05$ ); No statistical comparison for plaque sizes at $0.3 \%$ soft agar level could be performed, as plaque sizes were found to be less than $1.0 \mathrm{~mm}$ at all concentration of $\mathrm{CaCl}_{2}$ and $\mathrm{MgSO}_{4}$
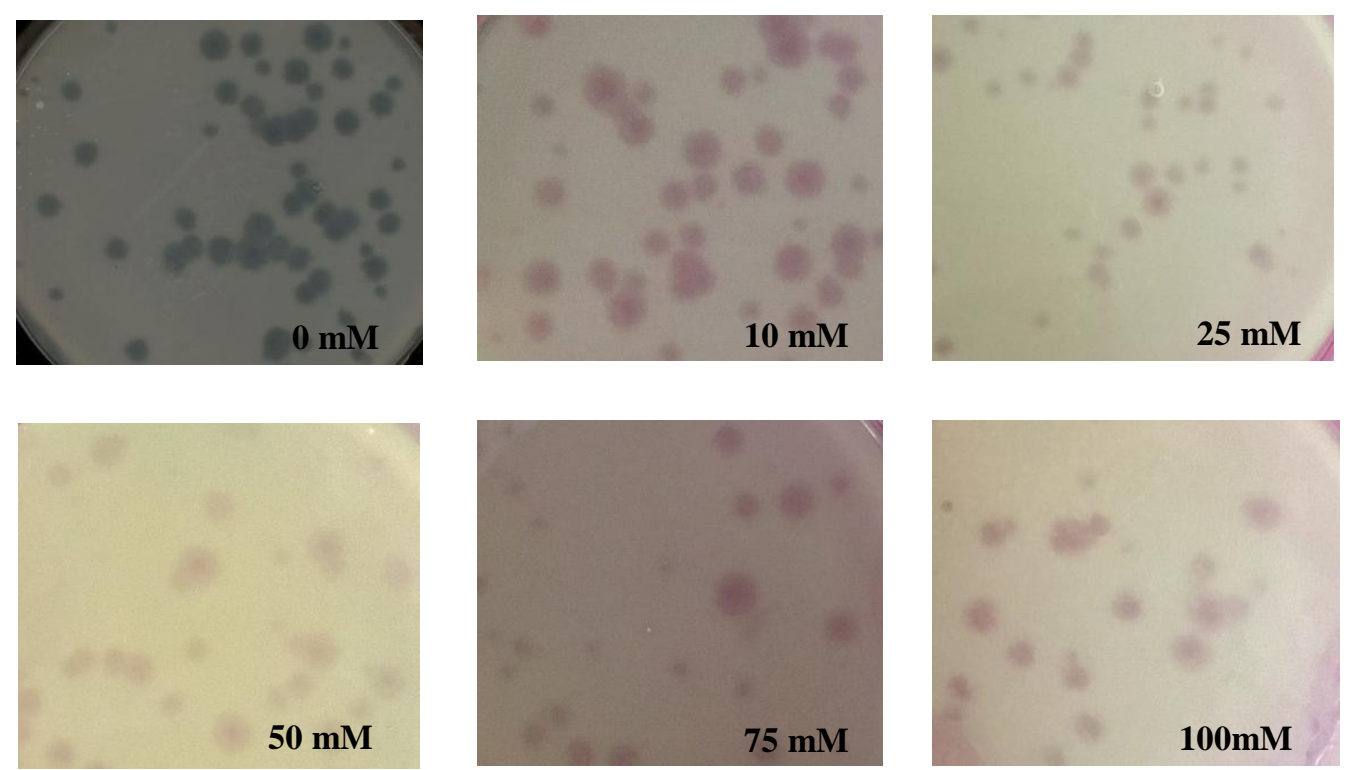

Fig.1 Plaque formation by Aeromonas hydrophila lytic D9 phage at $0.2 \%$ soft agar level with different concentrations of $\mathrm{CaCl}_{2}$ and $\mathrm{MgSO}_{4}$

In conclusion, this study determined the optimized plaque forming conditions for a A.hydrophila lytic phage. Addition of $10 \mathrm{mM}$ $\mathrm{CaCl}_{2}$ and $\mathrm{MgSO}_{4}$ at $0.2 \%$ soft agar concentration resulted in optimum plaque sizes and counts. Optimization of plaque forming conditions is very much crucial to continue phage research, and the availability of published studies could be a useful start point to improve the double layer assays for poor plaque forming phages. 


\section{Acknowledgements}

The authors are grateful to the Dean, College of Fisheries, Guru Angad Dev Veterinary \& Animal Sciences University, Ludhiana, India for facilities and support. This work was supported by Rashtriya Krishi Vikas Yojana (RKVY) Grant RKVY-11:I3 "Development of biotechnological intervention strategies to enhance the safety and shelf life of fishery products".

\section{References}

Abedon, S.T. and Yin, J. 2009. Bacteriophage plaques: theory and analysis. Methods Mol. Biol.501: 161-174.

Foddai, A., Elliott, C.T. and Grant, I.R. 2009. Optimization of a Phage Amplification Assay To Permit Accurate Enumeration of Viable Mycobacterium avium subsp. paratuberculosis Cells. Appl. Environ. Microbiol. 75: 3896-3902.

Kropinski, A.M., Mazzocco, A., Waddell, T. E., Lingohr, E. and Johnson, R. P. 2009. Enumeration of bacteriophages by double agar overlay plaque assay. Methods Mol. Biol. 501: 69-76.

Ma, L., Green, S.I., Trautner, B.W., Ramig,
R.F. and Maresso, A.W. 2018. Metals Enhance the Killing of Bacteria by Bacteriophage in Human Blood. Sci. Rep. 8: 2326.

Mullan, M. 2002. Factors affecting plaque formation by bacteriophages. https://www.dairyscience.info/index.ph p/enumeration-of-lactococcalbacteriophages/factors-affecting-plaqueformation.html.

Santos, S.B., Carvalho, C.M., Sillankorva, S., Nicolau, A., Ferreira, E.C. and Azeredo, J. 2009. The use of antibiotics to improve phage detection and enumeration by the double-layer agar technique. BMC Microbiol. 9: 148.

Serwer, P., Hayes, S.J., Thomas, J.A. and Hardies, S. C. 2007. Propagating the missing bacteriophages: a large bacteriophage in a new class. Virol. J. 4: 21.

Vinod, M.G., Shivu, M.M., Umesha, K.R., Rajeeva, B.C., Krohne, G., Karunasagar, I. and Karunasagar, I. 2006. Isolation of Vibrio harveyi bacteriophage with a potential for biocontrol of luminous vibriosis in hatchery environments. Aquaculture. 255: $117-124$.

\section{How to cite this article:}

Sumeet Rai, Anuj Tyagi, B. T. Naveen Kumar and Niraj Kumar Singh. 2020. Optimization of Plaque Forming Conditions for an Aeromonas hydrophila Lytic Bacteriophage. Int.J.Curr.Microbiol.App.Sci. 9(06): 3764-3768. doi: https://doi.org/10.20546/ijcmas.2020.906.445 